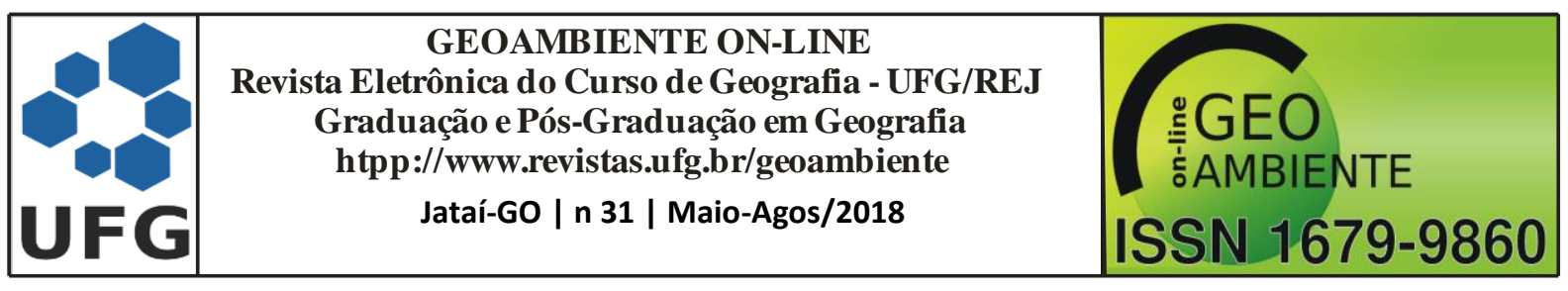

\title{
ESTUDO E ZONEAMENTO DAS FORMAS DE RELEVO DO MUNICÍPIO DE SÃO VICENTE DO SUL, RS
}

\author{
Luís Eduardo de Souza Robaina ${ }^{1}$, Romario Trentin ${ }^{1}$ \\ (1 - Universidade Federal de Santa Maria, Doutor, Docente do Programa de Pós-Graduação \\ em Geografia, lesrobaina@yahoo.com.br, romario.trentin@gmail.com)
}

Resumo: Os estudos e a compartimentação da paisagem através das formas, definidas pelo relevo, e sua composição entendida como os elementos do substrato rochoso e solos, com variações das características visuais e físicas, são fundamentais para compreender a dinâmica geomorfológica e auxiliar no manejo e planejamento de áreas agrícolas e urbanas. O presente trabalho tem como objetivo a compartimentação fisiográfica do município de São Vicente do Sul, através de combinações de elementos em ambiente de SIG. Foram definidas cinco unidades fisiográficas: associado aos rios que drenam o município as Unidades Várzea do Rio Ibicuí e Várzea do rio Jaguari, sendo que a primeira está representada na parte Sul do município drenada pela bacia hidrográfica do rio Ibicuí, e a segunda drena a porção Norte do município; associado ao relevo de colinas a Unidade colinas suavemente onduladas, com declividades média de 5\%, e que é a mais representativa do município, e a Unidades colinas onduladas representada por um relevo com declividades entre 8 e 12\%; além dessas, a unidade de Morros e Morrotes de correntes da erosão regressiva ou recuo das escarpas do Planalto, representada por formas isolados, conhecidos regionalmente como Cerros.

Palavras-Chaves: Mapeamento; Unidades de relevo; Cruzamento de informações

\section{LANDFORMS STUDY AND ZONING OF THE MUNICIPALITY OF SÃO VICENTE DO SUL, RS}

Abstract: Landscape studies and compartmentalization through shapes, defined by relief, and composition understood as elements of rocky substrate and soils with variations of visual and physical characteristics, are fundamental to understand geomorphological dynamics and assist in the management and planning of agricultural and urban areas. The present work aims at the physiographic compartmentalization of the São Vicente do Sul municipality, through 


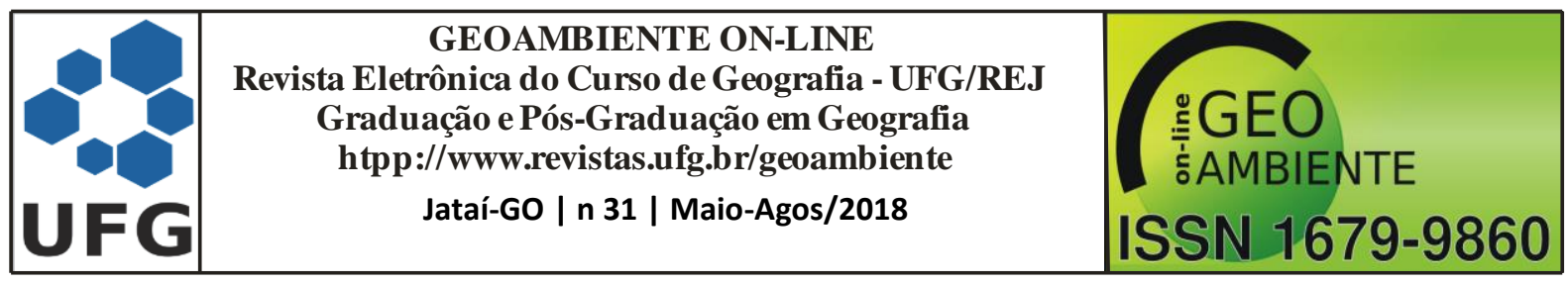

combinations of elements in a GIS environment. Five physiographic units were defined: associated to the rivers that drain the municipality the Flood Units of the Ibicuí River and of the Jaguari River, where the first one is represented in the Southern part of the municipality drained by the Ibicuí river basin, and the second drains the Northern portion of the municipality; associated with the relief of hills to the unit gently rolling hills, with slopes around 5\%, and which is the most representative of the municipality and the units undulated hills represented by a relief with slopes between 8 and 12\%; besides these, the Buttes unit resulting from the regressive erosion or retreat of the Plateaus escarpments, represented by isolated forms, known regionally as Cerros.

Keywords: Mapping; Relief units; information crossing

\section{ÉTUDE ET ZONAGE DES FORMES DE RELIEF DE LA MUNICIPALITÉ DE SÃO VICENTE DO SUL, RS}

Résumé: Les études et la compartimentation du paysage par les formes, définies par le relief, et sa composition comprise comme éléments du substrat rocheux et des sols, avec des variations des caractéristiques visuelles et physiques, sont fondamentales pour comprendre la dynamique géomorphologique et aider à la manipulation et planification des zones agricoles et urbaines. Le présent travail vise à la compartimentation physiographique de la ville de São Vicente do Sul, à travers des combinaisons d'éléments dans un environnement SIG. Cinq unités physiographiques ont été définies: associées aux rivières qui drainent la municipalité, les unités de plaine de la rivière Ibicuí et les unités de la rivière Jaguari, avec le premier est représenté dans la partie sud de la municipalité drainée par le bassin de la rivière Ibicuí, et le second draine la partie Nord de la municipalité; associé au relief des collines à l'unité doucement ondulé, avec des pentes autour de 5\%, le plus représentatif de la municipalité et les unités collines ondulées représentées par un relief avec des pentes entre 8 et 12\%; aussi l'unité de Buttes, résultant de l'érosion régressive ou du retrait des escarpements du Plateaus, représentés par des formes isolées, connues sous le nom de Cerros.

Mots-clés: Cartographie; Unités de relief; São Vicente do Sul 


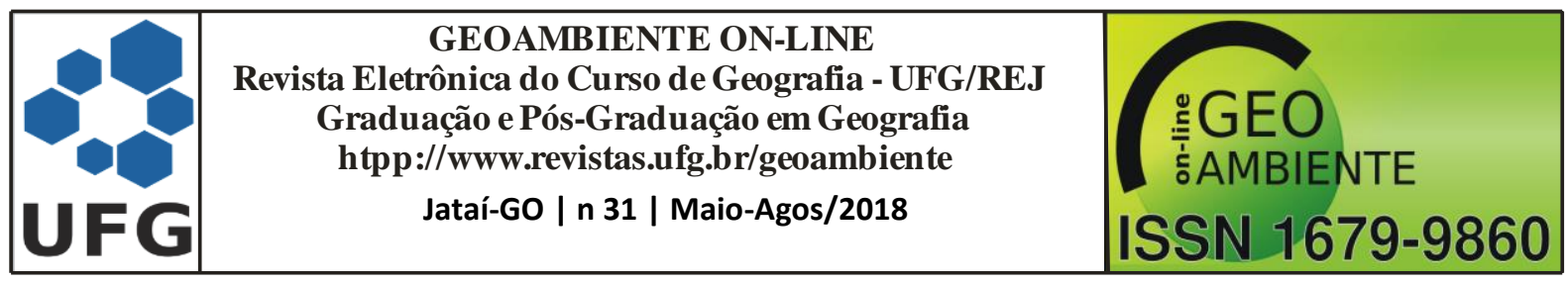

\section{INTRODUÇÃO}

A análise fisiográfica relaciona as propriedades externas de uma paisagem com suas características internas, expressas nos perfis de solos são instrumentos básicos para planos de gestão, que visem à utilização racional do ambiente e à compreensão dos processos naturais atuantes (SOUZA E JIMÉNEZ-RUEDA, 2007).

Trabalhos de levantamento e compartimentação fisiográfica têm sido realizados por vários pesquisadores para compreender a dinâmica geomorfológica e auxiliar no manejo e planejamento de áreas agrícolas e urbanas. Como exemplo citam-se o trabalho de Olivera et al. (2011) que apresenta a caracterização fisiográfica da Bacia Hidrográfica do Córrego Jandaia - Jandaia do Sul/PR, utilizando mapas temáticos de hidrografia, hipsometria, declividade, exposição de vertentes, perfis transversais e longitudinais, com apoio de técnicas de geoprocessamento; Diniz et al. (2014) que analisaram a geologia, geomorfologia e classes de solos para delimitação, caracterização e classificação das paisagens e suas respectivas unidades fisiográficas da região norte do Estado do Ceará; Rigon e Passos (2014) caracterizaram os aspectos físicos que compõem a paisagem da bacia hidrográfica do rio Pirapó, através de informações sobre a geologia, relevo, solos e aspectos climáticos e; Viana et al. (2017) que identificaram e analisaram as potencialidades, as limitações e as vulnerabilidades usando como base os aspectos fisiográficos e socioeconômicos do município de Picos/Piauí.

No Rio Grande do Sul, Caldas (1938) e Nogueira (1948) desenvolveram os primeiros estudos sobre características fisiográficas do estado. Em 1954, Chebataroff apresentou uma divisão fisiográfica do Uruguai e do Rio Grande do Sul, acrescentando duas novas regiões e subdividindo em sub-regiões. O autor apresentou, pela primeira vez, a região denominada Cuesta basáltica de Haedo no oeste do estado. Usando como base este trabalho, em 1970, Müller Filho propôs a divisão do estado em: Planalto, Cuesta de Haedo, Depressão Central, Escudo e Planície Costeira. Nessa compartimentação observa-se que o município de São Vicente do Sul (SVS), se localiza na Depressão Central do estado. No trabalho sobre a compartimentação do estado realizado pelo Projeto RADAMBRASIL incorporado pelo IBGE (1986), o município de SVS se localiza na região geomorfológica denominada Depressão Central Gaúcha, na unidade Depressão do rio Ibicuí - rio Negro. 


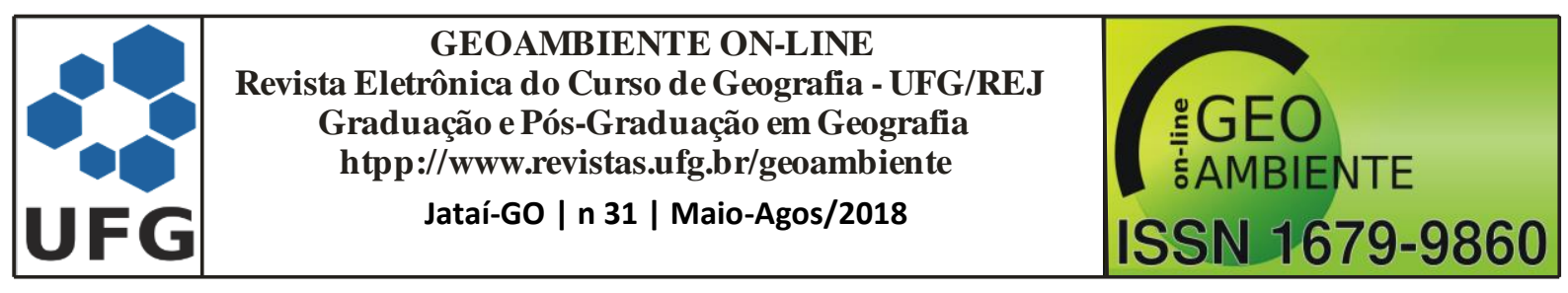

Mais recentemente, Robaina et al. (2010) determinam que o muncipio de São Vicente do Sul está representado pelos modelados da Depressão Periférica, mais especificamente na Depressão do Ibicuí, constituindo os modelados de Patamares Residuais em Arenitos, Relevo Ondulado em Rochas Friáveis e de Áreas Planas Aluviais.

O presente trabalho teve como objetivo a compartimentação fisiográfica do município de SVS, que foi desenvolvida através de cruzamentos em SIG, baseado em árvores de decisão, analisando os elementos do meio que possuem composição (litologia e solos) e uma forma (relevo) com variações das características visuais e físicas.

São Vicente do Sul (Figura 1) está localizada na região central do estado, definido

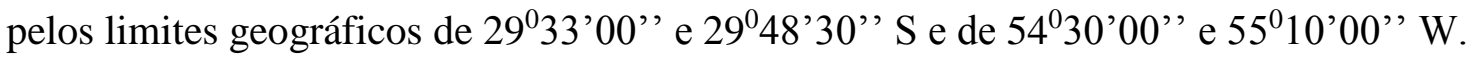

Figura 1 - Localização do município de São Vicente do Sul

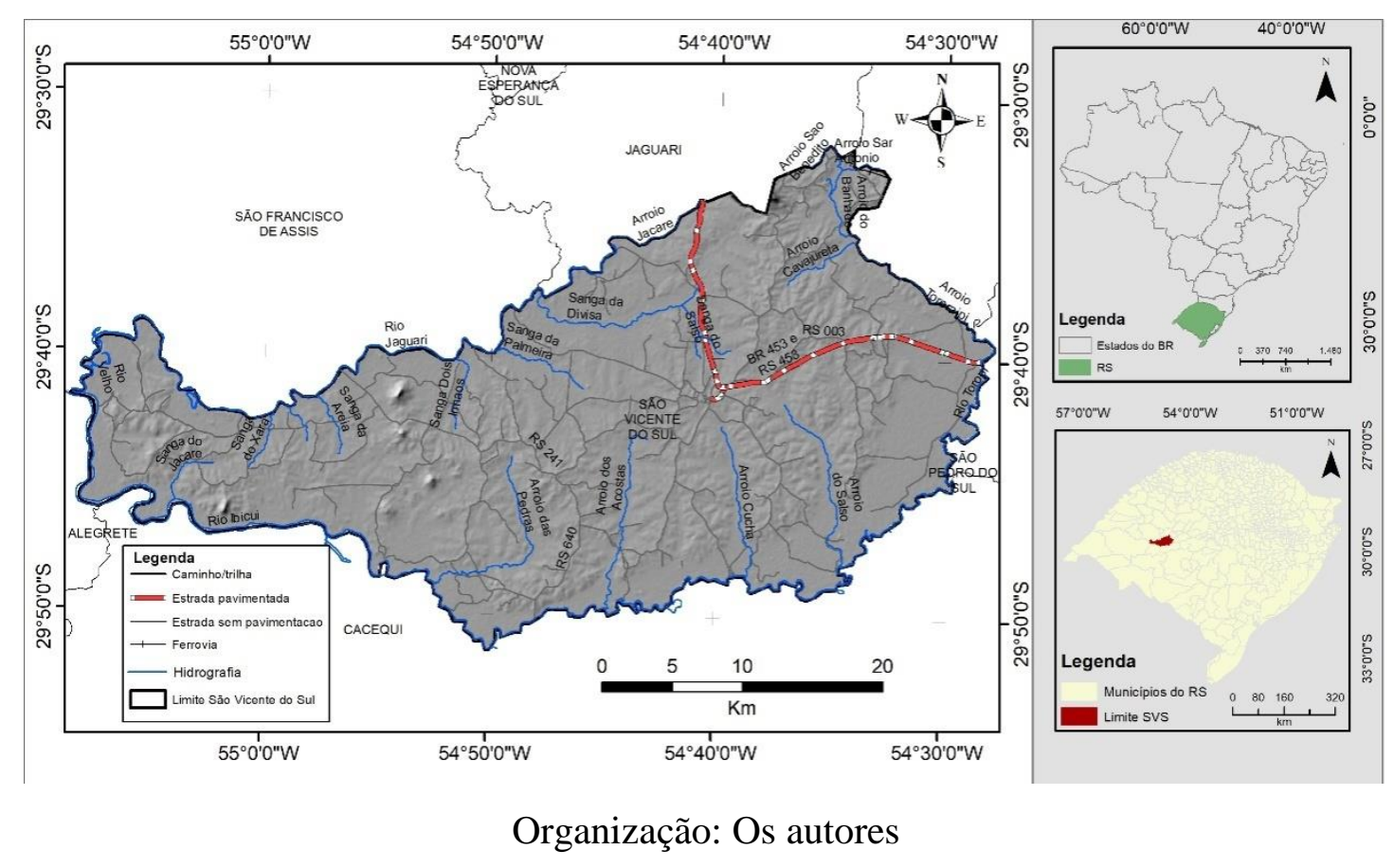

\section{METODOLOGIA}

Uma das base cartográficas utilizadas no trabalho, com a finalidade de espacialização do limite político administrativo, identificação da toponímias, hidrografia, sistema viários e auxílio nas informações topográficas, foi a Base Cartográfica Vetorial Contínua do Estado do Rio Grande do Sul, com escala 1:50.000 desenvolvida por (HASENACK, H.; WEBER, 2010) 


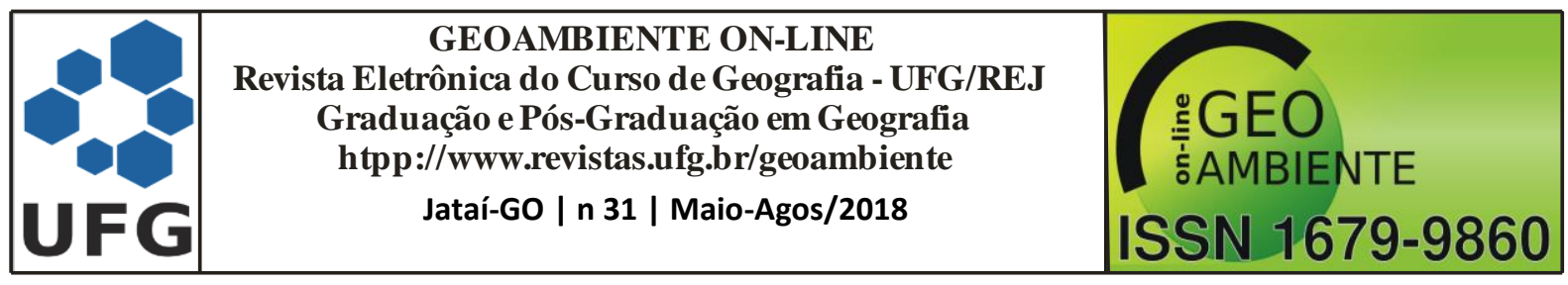

e a Malha Digital do IBGE (2010) também na escala 1:50.000, correspondendo as bases cartográficas utilizadas como dados primários para a elaboração dos mapas temáticos.

Para análise das hipsometrias no município e demais produtos topográficos e das características do relevo, utilizou-se o Modelo Digital de Elevação (MDE) da imagem SRTM (Shuttle Radar TopographyMission), com resolução espacial de 30m, obtidas junto ao United StatesGeologicalSurvey (USGS). Esta base cartográfica possibilitou a análise da variação hipsométrica do município, bem como serviu de referência para o mapeamento das declividades.

O mapa de declividade foi elaborado utilizando as classes proposta pelo Instituto de Pesquisas Tecnológicas (IPT, 1981), sendo: <2\%; 2-5\%; 5-15\%; e >15\%, através da ferramenta de análise espaciais e tridimensionais do SIG ArcGIS 10.1®.

A figura 2 mostra um breve fluxograma das etapas e cruzamentos dos mapas do presente trabalho, a fim de estabelecer a definição das unidades fisiográficas. A figura 3 mostra uma síntese dos mapas bases do município de SVS, utilizados na definição das unidades fisiográficas.

Figura 2 - Fluxograma metodológico das etapas do trabalho

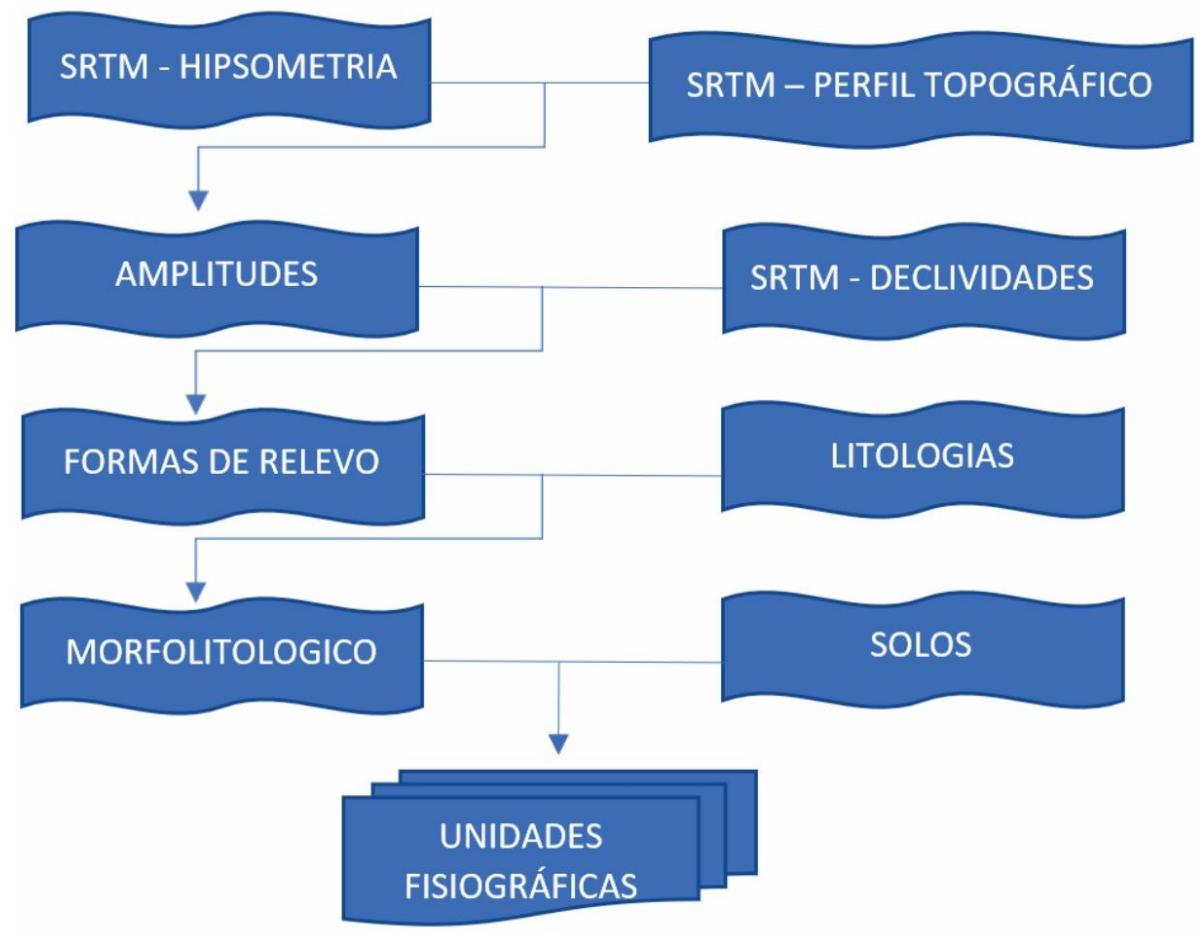

Organização: Os autores 


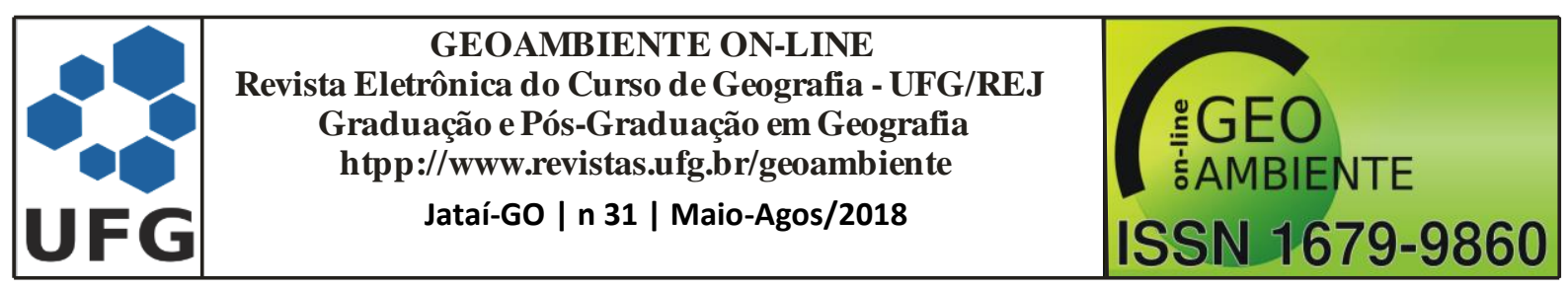

Figura 3 - Mapas bases utilizados na definição das unidades fisiográficas do município de São Vicente do Sul

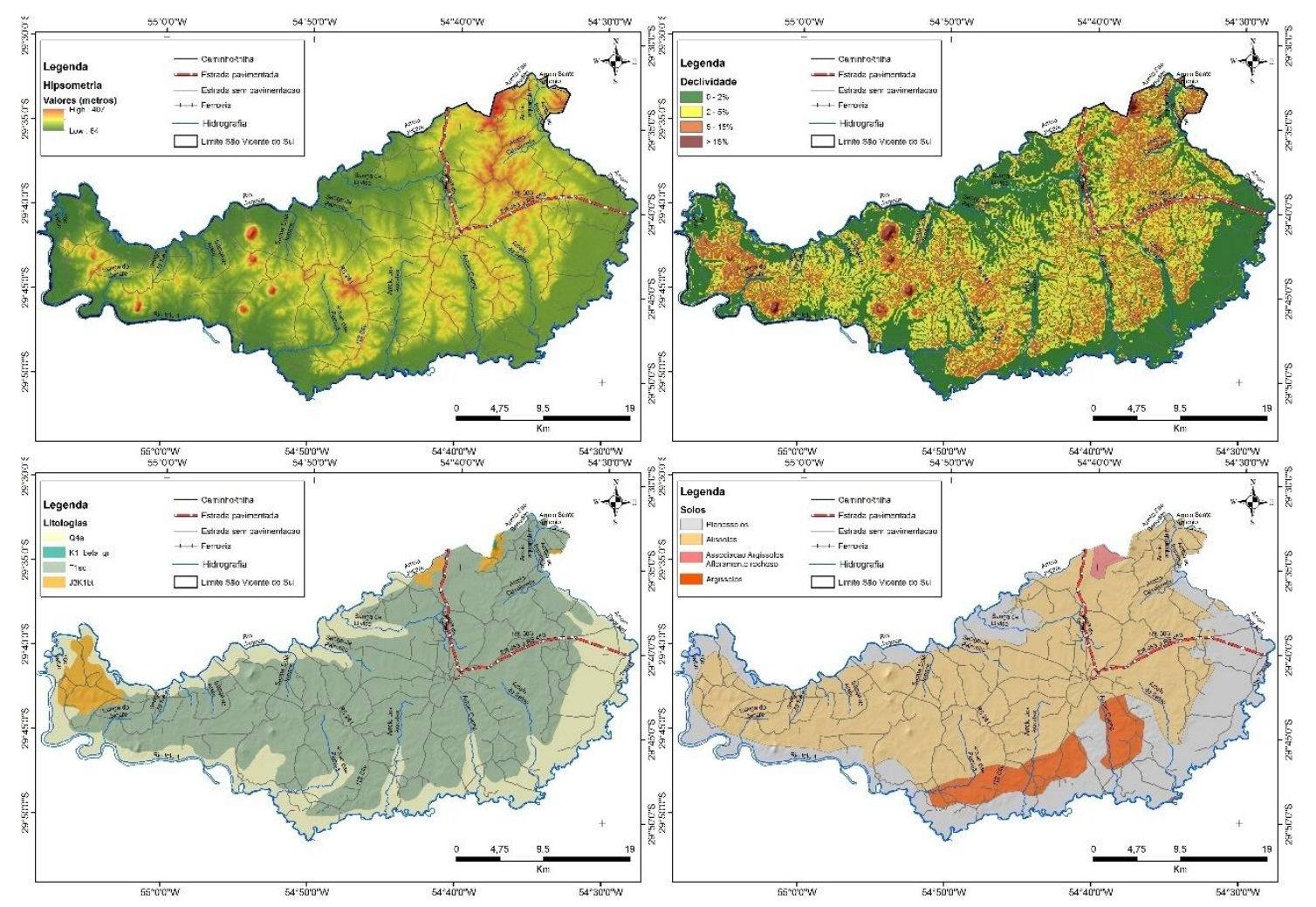

Organização: Os autores

Para a definição das formas de relevo, foi utilizada a metodologia adotada pelo Laboratório de Geologia Ambiental/UFSM, De Nardin e Robaina (2005), adaptado do Instituto de Pesquisas Tecnológicas IPT (1981). As classes definidas são: Morros, elevações com amplitude altimétrica superior a 100 metros e declividade de encostas superior a 15\%; Morrotes, elevações com amplitude altimétrica inferior a 100 metros e declividade de encostas superior a 15\%; Colinas, com áreas que representam declividade entre 5 e $15 \%$ e amplitude altimétrica inferior a 100 metros; Áreas Planas, com declividades menores que $2 \%$.

Os dados referente as litologias são disponíveis pela Companhia de Pesquisa de Recursos Minerais (CPRM), na escala 1:750.000, sendo conferidas com os dados encontrado em trabalhos de campo (WILDNER et al., 2006).

O mapa de solos do município foi realizado com base no mapa de solos do Estado do Rio Grande do Sul, em escala 1:250.000 realizado por (STRECK et al., 2008) tendo seu ajuste 


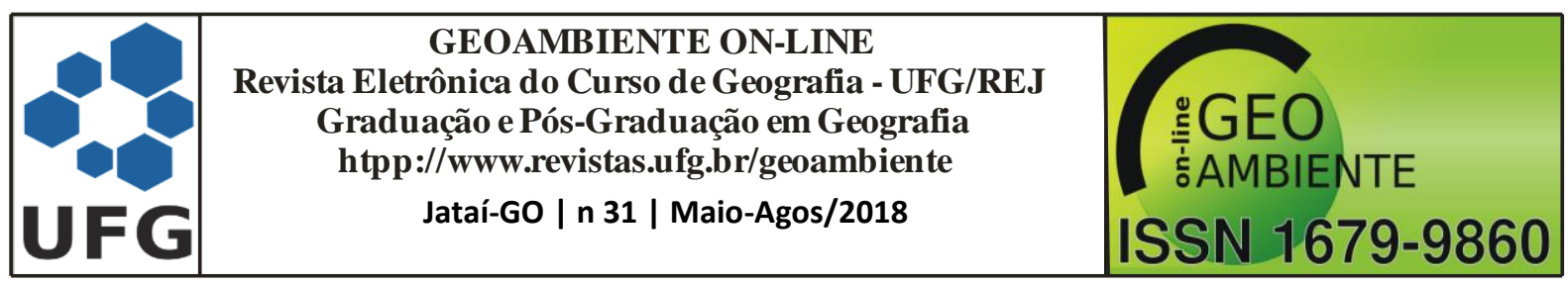

cartográfico, definido através dos levantamentos e mapeamentos de campo, semelhantes ao mapeamento geológico.

Através do cruzamento das formas de relevo com o mapa das litologias, obteve-se as unidades morfolitológicas do município. A definição das unidades fisiográficas ocorreu através do cruzamento do mapeamento de solos e do mapeamento das unidades morfolitológicas, sendo definidas cinco unidades fisiográficas assim denominadas: Várzea do Jaguari; Várzea do Ibicuí; Colinas suavemente onduladas; Colinas onduladas e; Morros e Morrotes.

\section{Caracterização da área de estudo}

Segundo o último censo demográfico do IBGE (2010) a população de São Vicente do Sul é de 8.840 habitantes. A economia baseia-se na agricultura e na pecuária, sendo a principal cultura o arroz e a soja.

O município de São Vicente do Sul é banhado por 16 sub bacias hidrográficas, sendo que as principais e mais relevantes drenagens da área são as do Rio Ibicuí e o Rio Jaguari, destaca-se que o divisor de águas entre as bacias hidrográficas desses rios perpassa pelo eixo latitudinal do município.

As altitudes no município, em geral estão abaixo de 150m, ocorrendo áreas com altitudes maiores que 150 metros em somente $2,75 \%$ de sua área territorial e, estão associadas aos morrotes isolados e as áreas da porção nordeste do município. As áreas com declividade entre $2 \%$ e $15 \%$ predominam no município, caracterizando o relevo de colinas. As formas de relevo atribuídas como morros e morrotes isolados de topos aguçados ou planos ocorrem entre as colinas.

As rochas mais antigas que afloram no município (Permiano Superior - Triássico) representam o avanço de depósitos continentais na Bacia do Paraná e são marcados por uma espessa sucessão flúvio-eólica que corresponde à Formação Sanga do Cabral (LAVINA, 1988). Essas rochas estão representadas por arenitos que se caracterizam pela presença comum de micas e por apresentar concreções carbonáticas. A outra sequência fluvial, encontrada no município, ocorre sobreposta a anterior, formando camadas no topo de morros e morrotes, constituindo a porção mantenedora do relevo. Corresponde a um substrato identificado por uma sequência de arenitos com grânulos associado a sequência pelíticas, 


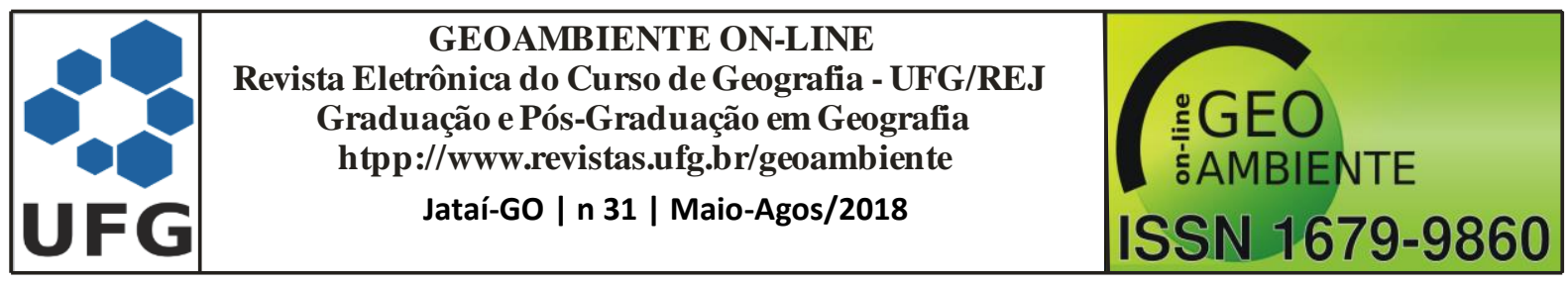

fluviais, com a coesão relacionada a concentração de óxido de ferro e, por vezes, sílica, como cimento. Essa litologia está associada à sequência litoestratigráfica que Wildner et al. (2006) determinou como Formação Guará com sedimentação do Período Jurássico. As sequências geológicas mais recentes ocorrem nas áreas de acumulação, junto à planície de inundação, na calha dos arroios e ao longo de sua planície de inundação. Além desses, são identificados terraços fluviais que indicam um entalhamento das drenagens e a exposição de depósitos de canais em cotas topográficas mais elevadas que as atuais.

Os solos hidromórficos estão associados, principalmente, as várzeas dos grandes rios que marcam divisas do município, rio Jaguari e o rio Ibicuí. Em grande parte do município sobre um substrato de arenitos finos, em relevo de colinas ocorrem solos do tipo Argissolos. Nas porções mais finas, menos permeáveis dos arenitos, ocorrem Argissolos Bruno, enquanto, nas porções mais arenosas Argissolos Vermelhos.

\section{COMPARTIMENTAÇÃO FISIOGRÁFICA}

A definição das unidades fisiográficas ocorreu através do cruzamento dos mapas temáticos, sendo definidos, para o município de São Vicente do Sul, cinco unidades fisiográficas. A figura 4 mostra a espacialização das unidades fisiográficas no município e a Tabela 1 apresenta os dados quantitativos das porcentagens de área ocupada pelas unidades. Na figura 5 está apresentado uma prancha de fotografias tiradas durante os trabalhos de campo no município de São Vicente do Sul, exemplificando as unidades fisiográficas definidas.

\section{Unidade Várzea do Rio Ibicuí}

Essa unidade é representada na parte Sul do município drenada pela bacia hidrográfica do rio Ibicuí, que apresenta 8 sub-bacias de $3^{\text {a }}$ ordem e diversas bacias de menor hierarquia, representadas, seguindo de Oeste para Leste, pelo arroio Sanga do Jacaré, arroio São Vicente, arroio das Pedras, arroio dos Acostas, arroio Cucha, o de maior área o arroio do Salso, arroio Cavajureta e o arroio Toraraipi. O relevo é formado por áreas planas com declividades, em geral inferiores a $2 \%$, ocorrendo em altitudes inferiores a 100 metros. Essas áreas respondem a ação fluvial do rio Ibicuí, com deposição de camadas argilosas na planície de inundação e arenosas próximas ao canal. 


\begin{tabular}{|c|c|c|}
\hline & $\begin{array}{c}\text { GEOAMBIENTE ON-LINE } \\
\text { Revista Eletrônica do Curso de Geografia - UFG/REJ } \\
\text { Graduação e Pós-Graduação em Geografia } \\
\text { htpp://www.revistas.ufg.br/geoambiente } \\
\text { Jataí-Go | n } 31 \text { | Maio-Agos/2018 }\end{array}$ & $\begin{array}{c}\text { ISSN 1679-9860 } \\
\text { IE }\end{array}$ \\
\hline
\end{tabular}

Figura 4 - Espacialização das unidades fisiográficas do município de São Vicente do Sul

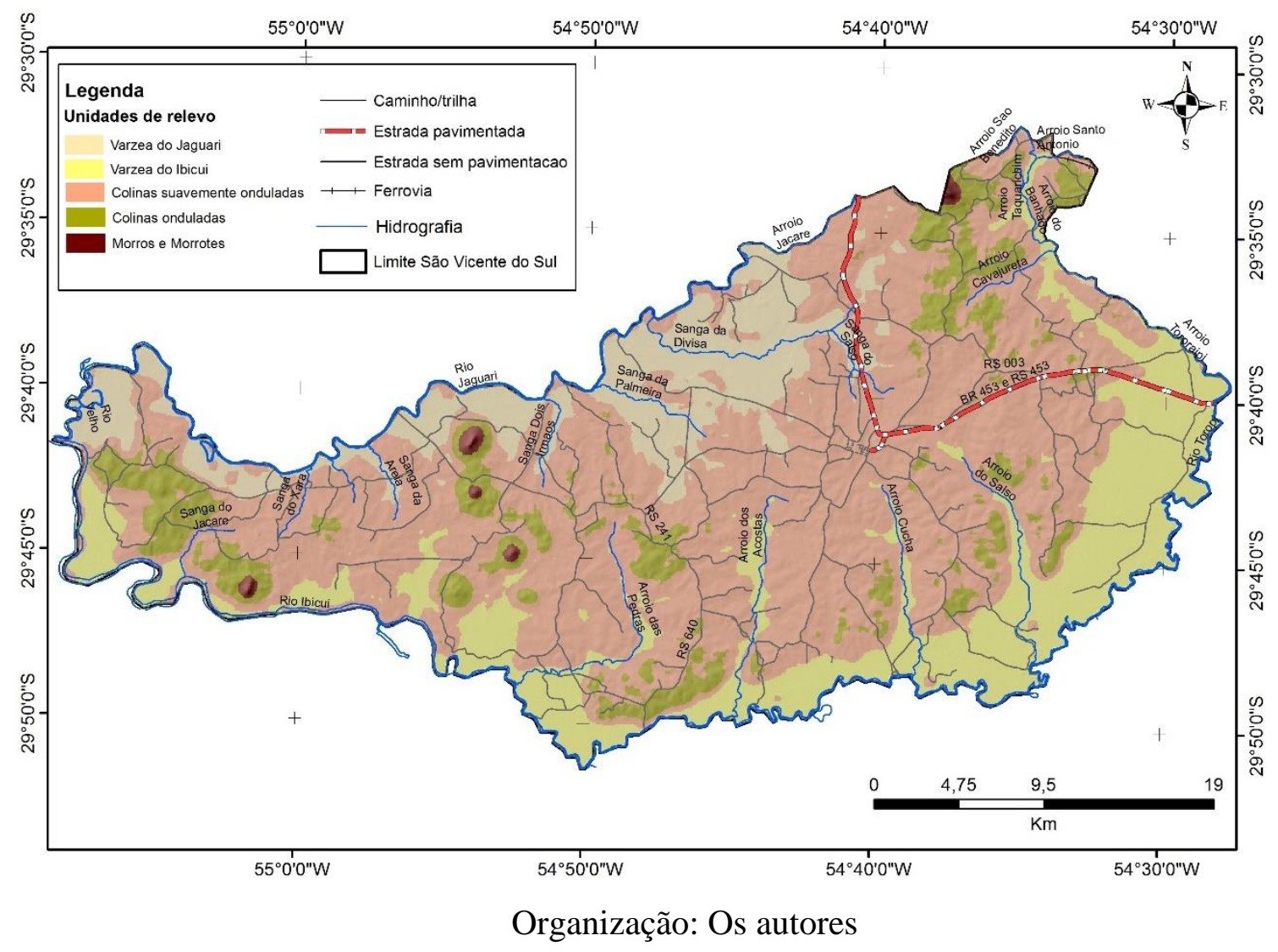

Tabela 1 - Dados quantitativos das unidades fisiográficas do município de São Vicente do Sul

\begin{tabular}{l|r|r}
\hline \multicolumn{1}{c|}{ Unidades } & \multicolumn{1}{c|}{ Área $\mathbf{~ k m}^{\mathbf{2}}$} & \multicolumn{1}{c}{ Porcentagem (\%) } \\
\hline Várzea do Ibicuí & 232,47 & 19,78 \\
\hline Várzea do Jaguari & 143,18 & 12,18 \\
\hline Morros e Morrotes & 5,12 & 0,44 \\
\hline Colinas suavemente onduladas & 673,48 & 57,31 \\
\hline Colinas onduladas & 120,96 & 10,29 \\
\hline
\end{tabular}

Organização: Os autores 


\begin{tabular}{|c|c|c|}
\hline & $\begin{array}{c}\text { GEOAMBIENTE ON-LINE } \\
\text { Revista Eletrônica do Curso de Geografia - UFG/REJ } \\
\text { Graduação e Pós-Graduação em Geografia } \\
\text { htpp://www.revistas.ufg.br/geoambiente } \\
\text { Jataí-Go | n } 31 \text { | Maio-Agos/2018 }\end{array}$ & $\begin{array}{c}\text { :GEO } \\
\text { JEAMBIENTE } \\
\text { G }\end{array}$ \\
\hline
\end{tabular}

Figura 5 - Fotografias de trabalhos de campo realizados no município. a) Afloramento do arenito da Formação Sanga do Cabral, com camadas onduladas cimentadas e coesas; b) Arenito vermelho, fino com laminação plano-paralela da Formação Sanga do Cabral; c) Relevo de colinas onduladas; d) Relevo de colinas suavemente onduladas com substrato de arenitos; e) Morrote com topo aguçado; f) Morro com topo plano (Cerro do Loreto), sustentado por arenito resistentes da Formação Guará; g) Áreas planas associadas às várzeas do Rio Ibicuí; h) Áreas planas associadas às várzeas do Rio Jaguari.
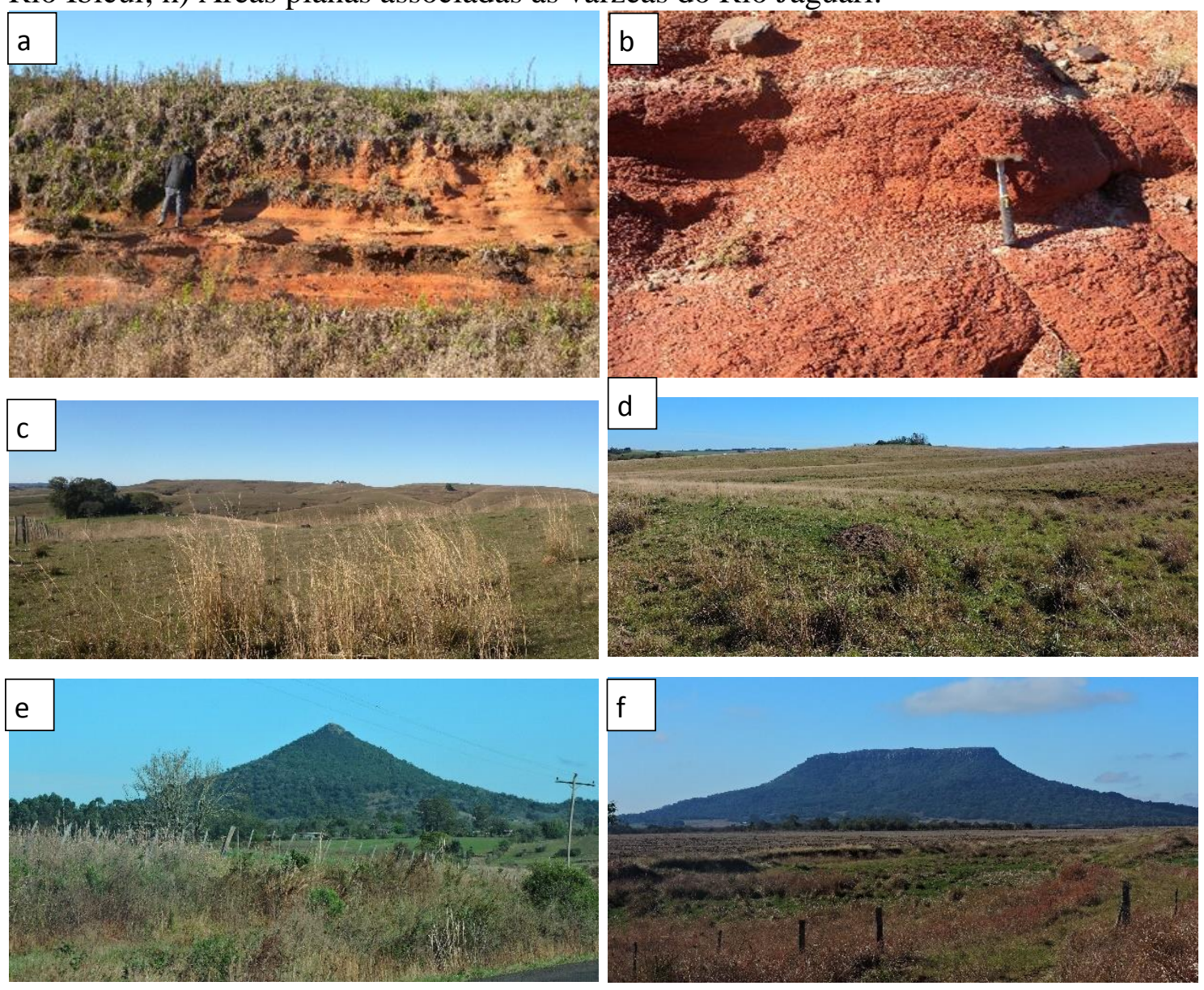

g

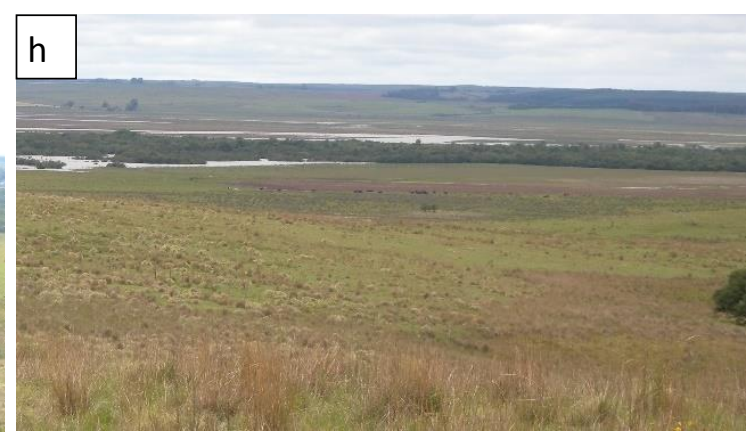

Fonte: Os autores

Os solos próximos ao rio são Gleissolos e sobre a várzea são os Planossolos. Ocorrem, ainda, sobre bancos arenosos associados ao canal fluvial solos arenosos mal desenvolvidos 


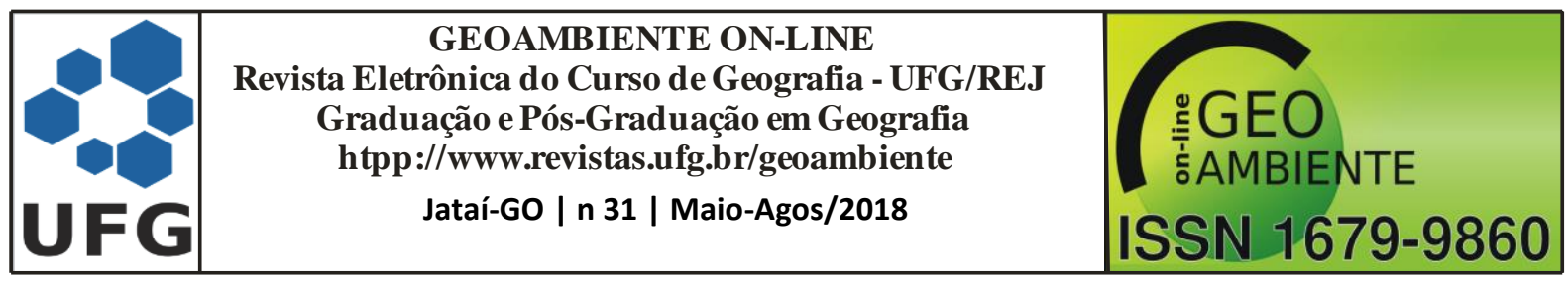

identificados como Neossolos Quartzarênicos Flúvicos. Espacialmente ocupa 232,47 km², o que representa $19,78 \%$ da área total do município. Processos de erosão de margem são significativas em áreas onde ações antrópicas modificam a dinâmica fluvial.

\section{Unidade Várzea do rio Jaguari}

O rio Jaguari, drena a porção Norte do município é um dos principais afluentes do rio Ibicuí. $\mathrm{Na}$ área é composto por 4 sub-bacias de pelo menos $3^{\mathrm{a}}$ ordem, as sub-bacias do arroio Sanga da Divisa, arroio Sanga da Palmeira, arroio Sanga Dois Irmãos e arroio Sanga da Areia. Essa unidade é de relevos planos com altitudes inferiores a 100 metros, com solos do tipo Gleissolos e Planossolos sobre um substrato de sedimentos depositados pelo rio Jaguari. Espacialmente ocupa $143,18 \mathrm{~km}^{2}$, o que representa $12,18 \%$ da área total do município. As erosões de margem são os principais processos que geram conflito com a ocupação do solo.

\section{Unidade de Morros e Morrotes}

Essa unidade é composta por Morros e Morrotes isolados, conhecidos regionalmente como Cerros. A principal característica são as encostas com declividades superiores a $15 \%$. A diferença, entre as formas, é que os Morros apresentam amplitude superior a $100 \mathrm{~m}$ e os Morrotes inferiores a $100 \mathrm{~m}$. Ocorrem, principalmente, na porção oeste do município e correspondem a $0,44 \%$ da área total do município.

Essa unidade é decorrente da erosão regressiva ou recuo das escarpas. Correspondem às maiores altitudes e declividades da área. Destacam-se o Cerro do Loreto (338 metros de altitude), Cerro do Agudo (288 metros), Cerro da Glória (278 metros) e Cerro do Belém (256 metros).

Estas feições são formadas por rochas sedimentares estratificadas, topos planos e encostas escarpadas, características de relevos tabulares mantidos por camadas resistentes da sequência de arenitos cimentados da Formação Guará. As formas Piramidais são formadas pela desagregação de rochas areníticas favorecidas pelas estruturas rúpteis subverticais. Apresentam um topo pontiagudo pela resistência parcial da rocha cimentada e, um significativo depósito de talús e colúvios na sua volta, formado por fragmentos de rochas e blocos oriundos das porções superiores das próprias feições. Ocorrem processos de movimentos de massa gerando depósitos de tálus nas bordas das encostas. 


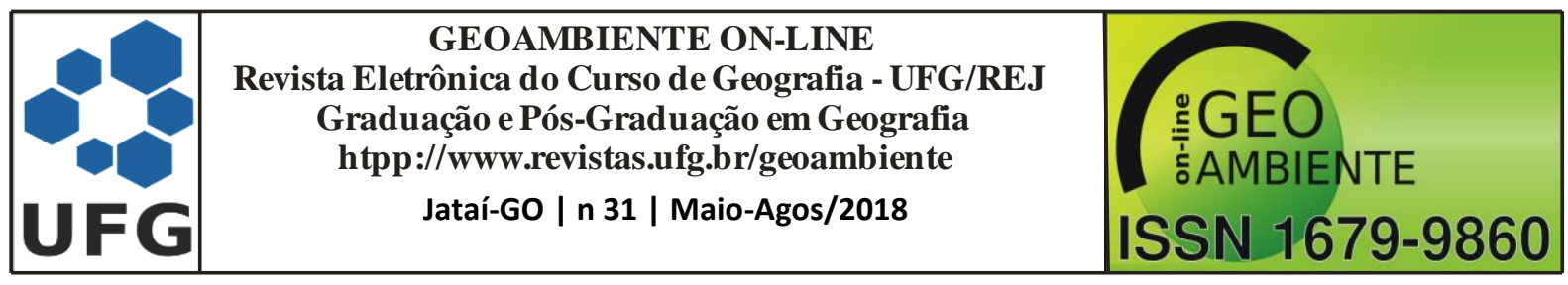

Unidade colinas suavemente onduladas

Essa unidade é a mais representativa do município, ocupando 673,48 km², correspondendo à $57,31 \%$ da área total do município. O relevo é constituído por formas definidas como colinas com declividades média de 5\% e amplitudes de 20 a 40m. O substrato é composto por arenitos finos de cor castanho-avermelhado com laminação plano-paralela e estratos cruzados acanalados que confere formas superficiais onduladas. Os solos possuem espessura aproximada de 1m, com Bt, variando de Argissolo Vermelho a Bruno. Os processos erosivos podem ser importantes nas porções convergentes da encosta gerando sulcos e ravinas.

\section{Unidades colinas onduladas}

Unidade representada por um relevo com declividades entre 8 e $12 \%$ e amplitudes de 40m. Os solos são do tipo Argissolos Vermelhos com espessura de 0,60 a 1,2m. O substrato é de arenitos vermelhos da Formação Sanga do Cabral, com porções de arenito grosso com cimentação carbonática que devido a coesão formam alguns degraus na encosta, que confere maior movimentação no relevo. Espacialmente ocupam 120,96 km² o que representa 10,29\% da área total do município. Na borda dos degraus gerados por diferença de resistência podem ocorrer ravinamentos.

\section{CONSIDERAÇÕES FINAIS}

A compartimentação fisiográfica apresentada, tem como objetivo estabelecer características quanto à sua configuração e modelado deste, a fim de subsidiar a compreensão de fatores atuantes na sua modelação.

O desenvolvimento cada vez maior de geotecnologias associadas à análise ambiental proporciona a incorporação de procedimentos e técnicas que auxiliem na análise e cruzamento de variáveis.

O município de São Vicente do Sul apresenta características de relevo, substrato rochoso e solos que permitiu, a partir da combinação usando Sistemas de Informações Geográficas e árvores de decisão, definir cinco unidades fisiográficas. Associado aos rios que drenam o município foram definidas duas unidades no relevo ondulado de colinas, e outras duas determinadas uma unidade nas formas residuais do Planalto, identificadas como Morros 


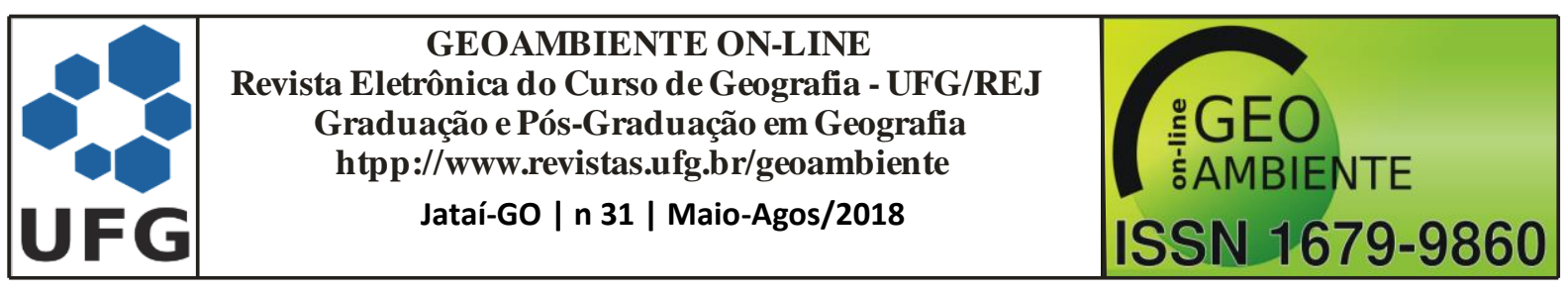

e Morrotes.

Estudos que identificam porções homogêneas de terreno são fundamentais para entendimento dos processos geomorfológicos e como as ações humanas podem interferir no ambiente. Dessa forma, permite analisar a relação entre processos superficias e os condicionantes ambientais, auxiliando o desenvolvimento de propostas de planejamento e uso do solos.

\section{REFERÊNCIAS BIBLIOGRÁFICAS}

CALDAS, J.T. Aspectos geomorfológicos do estado do Rio Grande do Sul. Revista do Instituto Histórico e Geográfico do Rio Grande do Sul. Porto Alegre 18(2): 253-281, 1938.

CHEBATAROFF, J. Regiones naturales de Rio Grande del Sur y del Uruguay - Anais da Associação dos Geógrafos Brasileiros, Volume VI, Tomo I (1951- 1952) - São Paulo, Brasil, 1954.

DE NARDIN, D.; ROBAINA, L.E.S. Mapeamento de unidades do relevo no oeste do RS: o caso da bacia hidrográfica do arroio Miracatú. São Paulo: Anais do XI Simpósio Brasileiro de Geografia Física Aplicada - 05 a 09 de setembro de 2005 - USP. 2005.

DINIZ, F.S.; RUEDA, J.R.J.; CARACRISTI, I. Estudo fisiográfico da região norte do estado do CE (rio Acaraú). Revista Geonorte, Edição Especial 4, V.10, N.1, p.298-302, 2014.

HASENACK, H.; WEBER, E. (ORG.). Base cartográfica vetorial contínua do Rio Grande do Sul - Escala 1:50.000. Porto Alegre. UFRGS Centro de Ecologia, , 2010. Disponível em: $<$ https://www.ufrgs.br/labgeo/index.php/dados-espaciais/250-base-cartografica-vetorialcontinua-do-rio-grande-do-sul-escala-1-50-000>. Acesso em: 7 abr. 2015.

INSTITUTO BRASILEIRO DE GEOGRAFIA E ESTATÍSTICA (IBGE). Projeto RADAMBRASIL. Levantamento de recursos naturais (Folha SH.22 Porto Alegre e parte das Folhas SH.21 Uruguaiana e SI.22 Lagoa Mirim). Instituto Brasileiro de Geografia e Estatística, Rio de Janeiro, CD-ROM. 1986.

INSTITUTO BRASILEIRO DE GEOGRAFIA E ESTATÍSTICA (IBGE). Malhas Digitais. Municípios 2010, Rio de Janeiro, 2010. Disponível em <http://downloads.ibge.gov.br/downloads_geociencias.htm>Acesso junho de 2015. 


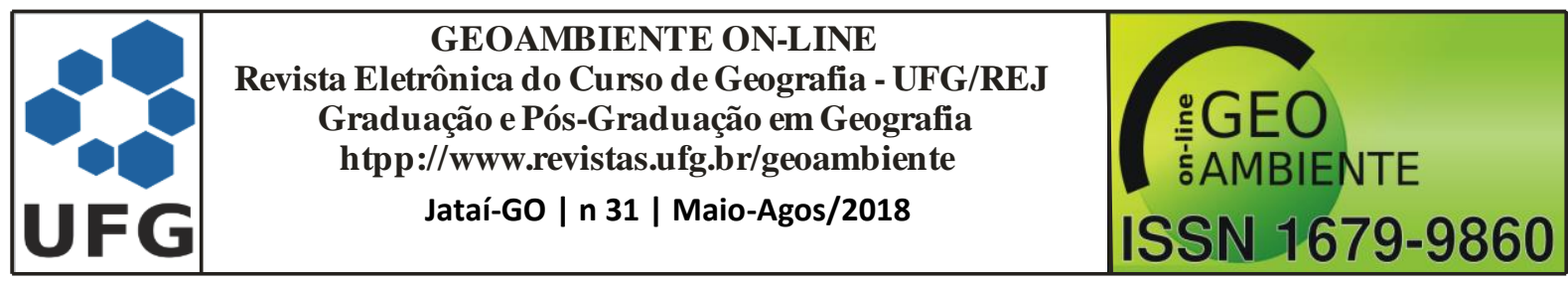

INSTITUTO DE PESQUISAS TECNOLÓGICAS DO ESTADO DE SÃO PAULO (IPT).

Mapa Geomorfológico do Estado de São Paulo. São Paulo: IPT, 1981. Volume I.

LAVINA, E. L. The Passa Dois Group. In:Anais do International Gondwana Symposium, 7, 1988. São Paulo. São Paulo: Instituto de Geociências, 1988. p. 24-30. 1988.

MÜLLER FILHO, I. L. Notas para o Estudo da Geomorfologia do Rio Grande do Sul. UFSM, Santa Maria, 1970.

NOGUEIRA, P. C. Regiões fisiográficas do Estado do Rio Grande do Sul. Boletim Geográfico, Rio de Janeiro, 6(64): 337-346, 1948.

OLIVERA, E.D.; CRESTANI A. E ALMEIDA, N. A. Caracterização fisiográfica da bacia de drenagem do Córrego Jandaia, Jandaia do Sul/PR. ACTA Geográfica, Boa Vista, v.5, n.10, jul./dez. de 2011. pp.169-183.

RIGON, O.; PASSOS, M. M.. Estudo Fisiográfico da Bacia Hidrográfica do rio Pirapó - PR.

Geografia (Londrina) v. 23, n. 1. p. 35 - 56, jan/jun, 2014.

ROBAINA, L. E. S.; TRENTIN, R.; BAZZAN, T.; RECKZIEGEL, E. W.; VERDUM, R.;

DE NARDIN, D. Compartimentação geomorfológica da bacia hidrográfica do Ibicuí, Rio Grande do Sul, Brasil: Proposta de classificação. Revista Brasileira de Geomorfologia, v. 11, n. 2, p. 11-23, 2010.

SOUZA A.A.; JIMÉNEZ-RUEDA J.R. Análise fisiográfica e morfoestrutural no reconhecimento de padrões de solos no município de Porto Velho-RO. In: Simpósio Brasileiro de Sensoriamento Remoto, 13, 2007. Anais. Florianópolis, INPE, 2007. CD-ROM. STRECK, E. V. et al. Solos do Rio Grande do Sul. 2. ed. Porto Alegre: Emater/RS, 2008.

UNITED STATES GEOLOGICAL SURVEY (USGS). USGS Global VisualizationViewer. Disponível em $:<<$ https://lpdaac.usgs.gov/data_access/glovis $>>$. Acesso em fevereiro de 2015.

VIANA, A. I. G.; NUNES, H. K. DE B.; SILVA, J. F. DE A.; CABRAL, L. J. R.S; AQUINO, C. M. S. DE; SANTOS, R.W.P. Caracterização fisiográfica e socioeconômica do município de Picos/PI: potencialidades, limitações e vulnerabilidades. InterEspaço. v. 3, n. 9 p. 88-108 maio/ago. 2017. 


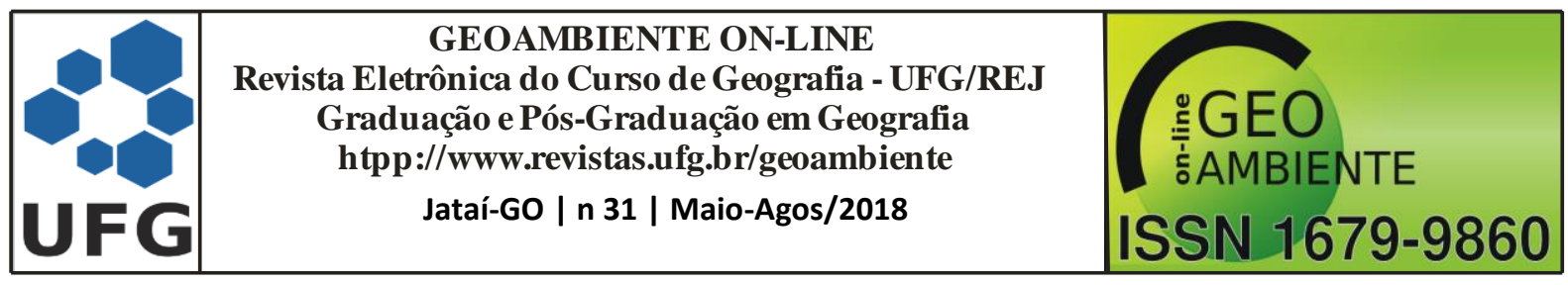

WILDNER, W; RAMGRAG, G. E.; LOPES R. C.; IGLESIAS, C. M. F. Mapa Geológico do Estado do Rio Grande do Sul.Escala 1:750000. CPRM, Serviço Geológico do Brasil. Porto Alegre, RS. 2006. 